\title{
Langerhans cell histiocytosis - a case report
}

\author{
Thiago Jeunon, M.D. ${ }^{1}$, Maria Auxiliadora Jeunon Sousa, M.D. ${ }^{2}$, \\ Nilton Santos-Rodrigues, M.D. ${ }^{2}$, Raquel Lopes, M.D. ${ }^{3}$

\footnotetext{
${ }^{1}$ Departments of Dermatology and Pathology, Hospital Federal de Bonsucesso and ID-Investigação em Dermatologia, Rio de Janeiro, Brazil

${ }^{2}$ ID-Investigação em Dermatologia, Rio de Janeiro, Brazil

${ }^{3}$ Department of Dermatology, Hospital Federal de Bonsucesso, Rio de Janeiro, Brazil
}

Key words: Langerhans cell histiocytosis, Langerhans cell, dermatology, histopathology, diabetes insipidus, hypogonadotropic hypogonadism

Citation: Jeunon T, Jeunon Sousa MA, Santos-Rodrigues N, Lopes R. Langerhans cell histiocytosis - a case report. Dermatol Pract Conc. 2012;2(1):4. http://dx.doi.org/10.5826/dpc.0201a04.

Editor: Harald Kittler, M.D.

Received: April 15, 2011; Accepted: August 1, 2011; Published: January 31, 2012

Copyright: (92012 Jeunon et al. This is an open-access article distributed under the terms of the Creative Commons Attribution License, which permits unrestricted use, distribution, and reproduction in any medium, provided the original author and source are credited.

Funding: None.

Competing interests: The authors have no conflicts of interest to disclose.

All authors have contributed significantly to this publication.

Corresponding author: Thiago Jeunon, M.D., Rua Barão de Mesquita 200/901 Tijuca, Rio de Janeiro - RJ, Brasil CEP:20540-003.

Tel/fax. +55 21 22340722. Email: thiago.jeunon@gmail.com.

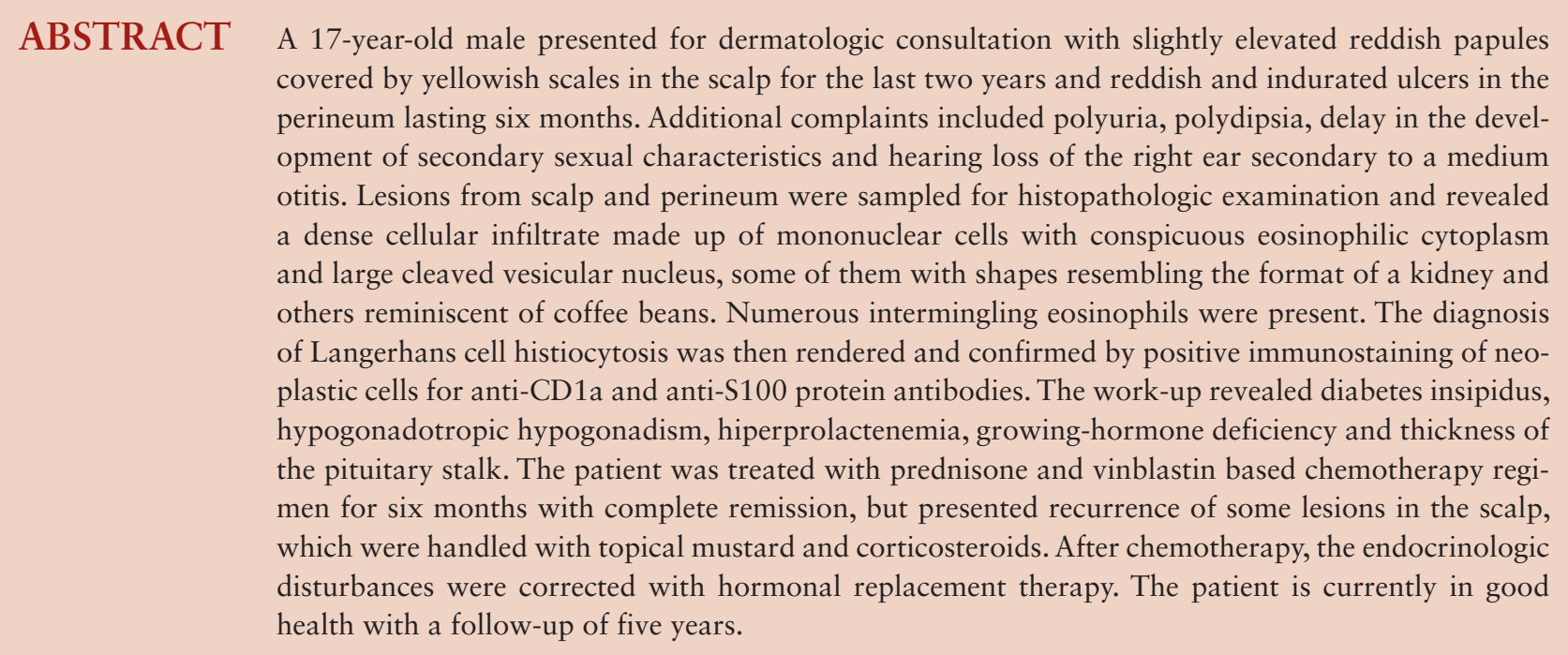




\section{Case presentation}

A 17-year-old white male presented to dermatological consultation with some asymptomatic, slightly elevated, erythematous papules covered by yellowish scales in the scalp vertex and temporal regions of two years' duration and small indurated ulcers with elevated borders at the perineum for six months (Figure 1). He complained of urinary frequency (up to 20 times/day) and excessive thirst (up to five liters of water/day) which were previously diagnosed as manifestations of primary polydipsia. There was a delay in the development of secondary sexual characteristics and a hearing loss in the right ear secondary to a medium otitis five years before the present consultation. He also complained of low stature in comparison to his high school peers. Actually, his height was $1.70 \mathrm{~m}$, being at the $25^{\text {th }}$ percentile according to the CDC 2000 growth chart (height versus age percentile graphic).

In addition to the skin lesions, physical exam showed slight bilateral gynecomastia, absence of terminal hairs in the beard area, axillae and pubis, as well as underdevelopment of testicles and penis (Figure 2). There were no lymph node or visceral enlargements. One scalp lesion and another one from the perineum were biopsied and both revealed a dense cellular infiltrate made up of mononuclear cells with conspicuous eosinophilic cytoplasm and large cleaved vesicular nucleus, some of them with shapes resembling the form of a kidney or of a coffee bean. The infiltrate was disposed in the superficial and middle dermis, assumed a band-like array and formed a sheet of cells in some areas. In other foci, in which neoplastic cells were sparser, numerous intermingling eosinophils were present (Figure 3). The surface of the perineal lesion was ulcerated, while in the lesion of the scalp some neoplastic cells were present between the keratocytes of an otherwise preserved epidermis. The diagnosis of Langerhans cell histiocytosis (LCH) was made based on morphologic criteria and confirmed by positivity of abnormal Langerhans cells by anti-CD1a and anti-S100 immunostains and negativity for anti-CD68.

The patient was admitted to the adolescent ward for additional investigation. He had mild anemia, normal basic biochemistry tests, negative serologic tests for syphilis and negative mycological tests of the lesions (direct exam and culture). Total skeleton radiograph and scintigraphy failed to show any bone lesion. Thorax radiography, abdominal ultrasonography and computerized tomography of the abdomen were normal. The setting of hypogonadotropic hypogonadism was defined by blood dosage of $\mathrm{LH}(0.10 \mathrm{mUI} / \mathrm{ml}$, normal range of $0.8-7,6)$, FSH $(0.53 \mathrm{mUI} / \mathrm{ml}$, normal range of $0.7-11.1)$, total testosterone $(27.0 \mathrm{ng} / \mathrm{dL}$, normal range: $241-827)$ and free testosterone $(0.50 \mathrm{pg} / \mathrm{dL}$, normal range of 120-550) and hyperprolactenemia by the high blood level
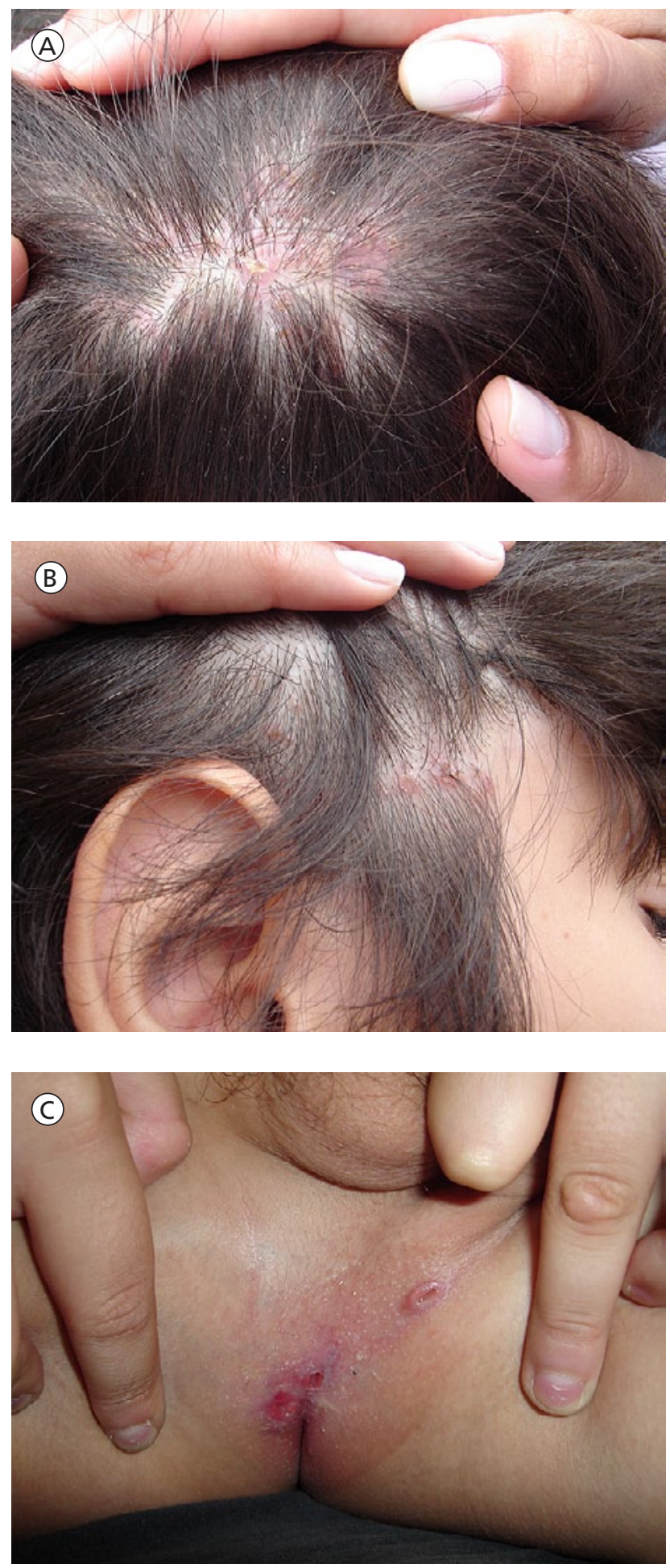

Figure 1. (A) Slightly elevated erythematous papules covered by yellowish scales in the vertex of the scalp. (B) Reddish scaly papules at the temporal region. (C) Three ulcers at the perineum, one with elevation of the borders. [Copyright: (O2012 Jeunon et al.]

of prolactin (32.6 ng/ml, normal range of 4.6-21.4). Diabetes insipidus was confirmed by water restriction test, in which the patient was unable to concentrate the urine, in spite of an increase of concentration of blood sodium from 139-149 $\mathrm{mEq} / \mathrm{L}$ and development of arterial hypotension. All these parameters were reversed after administration of 

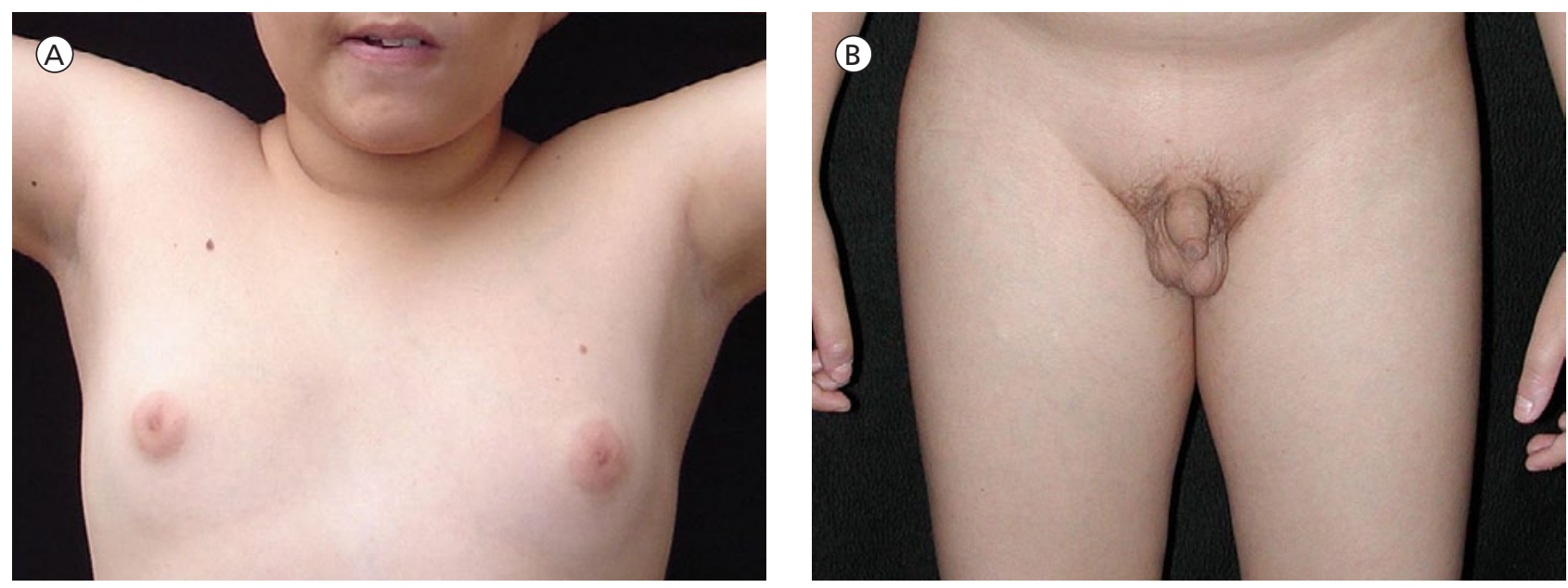

Figure 2. (A) Slight bilateral gynecomastia and absence of terminal hairs in beard area and axillae. (B) Underdevelopment of genitalia in relation to age. [Copyright: (02012 Jeunon et al.]

anti-diuretic hormone analog, which the patient continues to take. An insulin-induced hypoglycemia provocative test demonstrated GH deficiency, but cortisol secretion was preserved. Blood TSH and free T4 were within the normal range. Magnetic resonance imaging of the sella turcica showed thickening of the pituitary stalk and size reduction of the pituitary, suggesting infiltration of the neurohypophysis by the abnormal Langerhans cells. There was no indication at the MRI of other pathologic process that could explain the endocrinologic disturbances. The final diagnosis was of LCH with involvement of the skin, the pituitary stalk (diabetes insipidus and hyperprolactenemia), and the anterior pituitary (hypogonadotropic hypogonadism and GH deficiency). The patient was treated with a chemotherapy regimen consisting of an induction phase with prednisone $40 \mathrm{mg} / \mathrm{m}^{2} /$ day every day for four weeks with withdrawal for two additional weeks and vinblastin $6 \mathrm{mg} / \mathrm{m}^{2}$ IV bolus once a week in the first six weeks. The consolidation phase lasted six months with five days of prednisone $40 \mathrm{mg} / \mathrm{m}^{2} /$ day and one application of vinblastin $6 \mathrm{mg} / \mathrm{m}^{2}$ IV bolus every three weeks. The patient experienced complete remission (Figure 13), and after the end of chemotherapy his puberty was induced by hormonal replacement therapy. Some months later, there was recurrence of lesions in the scalp confirmed on histopathologic grounds, which were successfully treated with topical corticosteroid and nitrogen mustard. The patient is currently in good health with a follow up of six years.

\section{Conclusion}

$\mathrm{LCH}$ is a considerably rare disease with 4.1-4.6 cases for each million children and is regarded as an idiopathic monoclonal proliferation of abnormal Langerhans cells [1]. Whether it is an inflammatory condition or a true neoplasm has been a matter of debate [2,3]. Those cells may infiltrate and affect any organ, such as skin, pituitary, bones, lungs, brain and lymph nodes, liver, spleen, or hematopoietic system. LCH presents with a broad spectrum of manifestations, varying from solitary lesions to disseminated, multisystem, life-threatening disease. Previous to the unifying concept advanced by Jaffe and Lichtenstein in 1944, some clinical syndromes had been independently described and later named eponymously [4]. Letterer-Siwe disease usually occurs in children under one year of age, has a poor prognosis and manifests itself as fever and skin rash, hepatomegaly, splenomegaly, pulmonary symptoms and anemia [5]. Hand-Schuller-Christian disease usually affects children older than three years old and is defined by the triad of exophthalmos, diabetes insipidus and skull defect. Eosinophilic granuloma refers to a single bone lesion in older children, teenagers or adults with symptoms of pain, swelling and, eventually, pathologic fracture, but with a very good prognosis $[1,5,6]$. However, many cases do not fit exactly in any of these late descriptions, which have more historical importance than clinical usage and, currently, cases have been classified into two major categories:

(1) "Single-system" LCH, subdivided further into unifocal (single lesion on bone, skin or lymph node) or multifocal (multiple lesions on bone or multiple lymph nodes) and

(2) "Multi-system" LCH, when disease affects two or more different organs, with subdivision into low-risk or highrisk groups depending on the absence or presence of involvement of liver, lungs, spleen or hematopoietic system [2].

LCH affects the skin in about $40 \%$ of cases. Typically, the cutaneous lesions consist of small translucent, skin-colored, yellowish, red, or even purpuric scaly papules, usually located on the trunk and scalp. Vesicles and pustules may also come into being. Nodular lesions are particularly pres- 

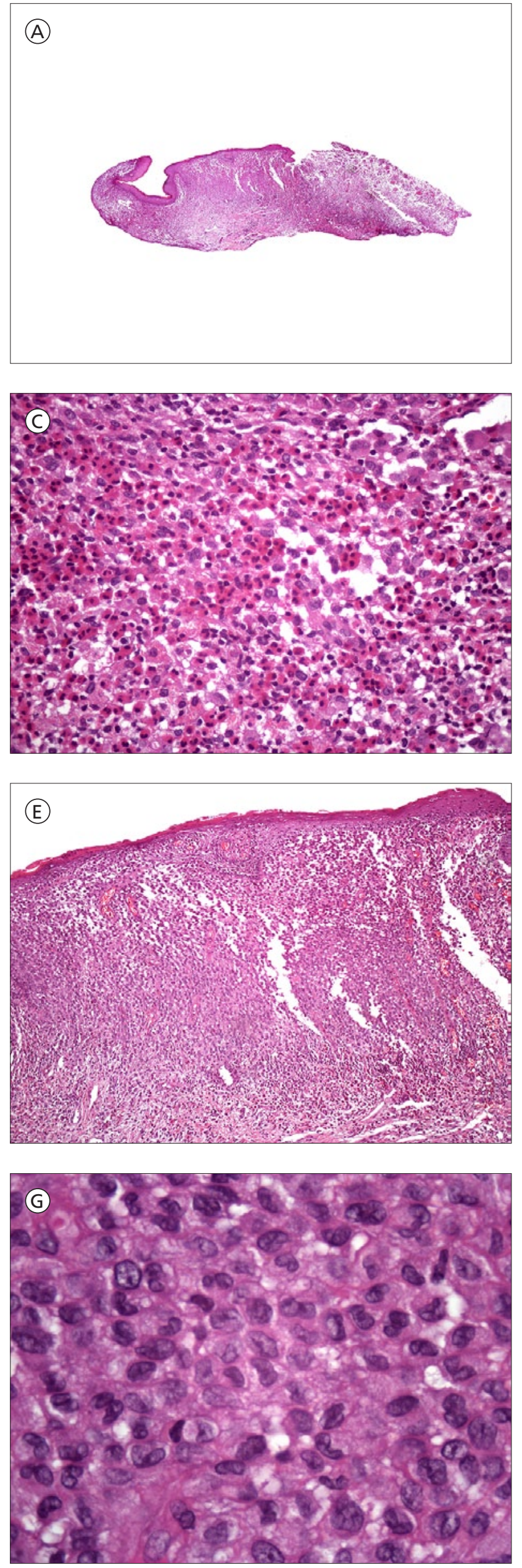
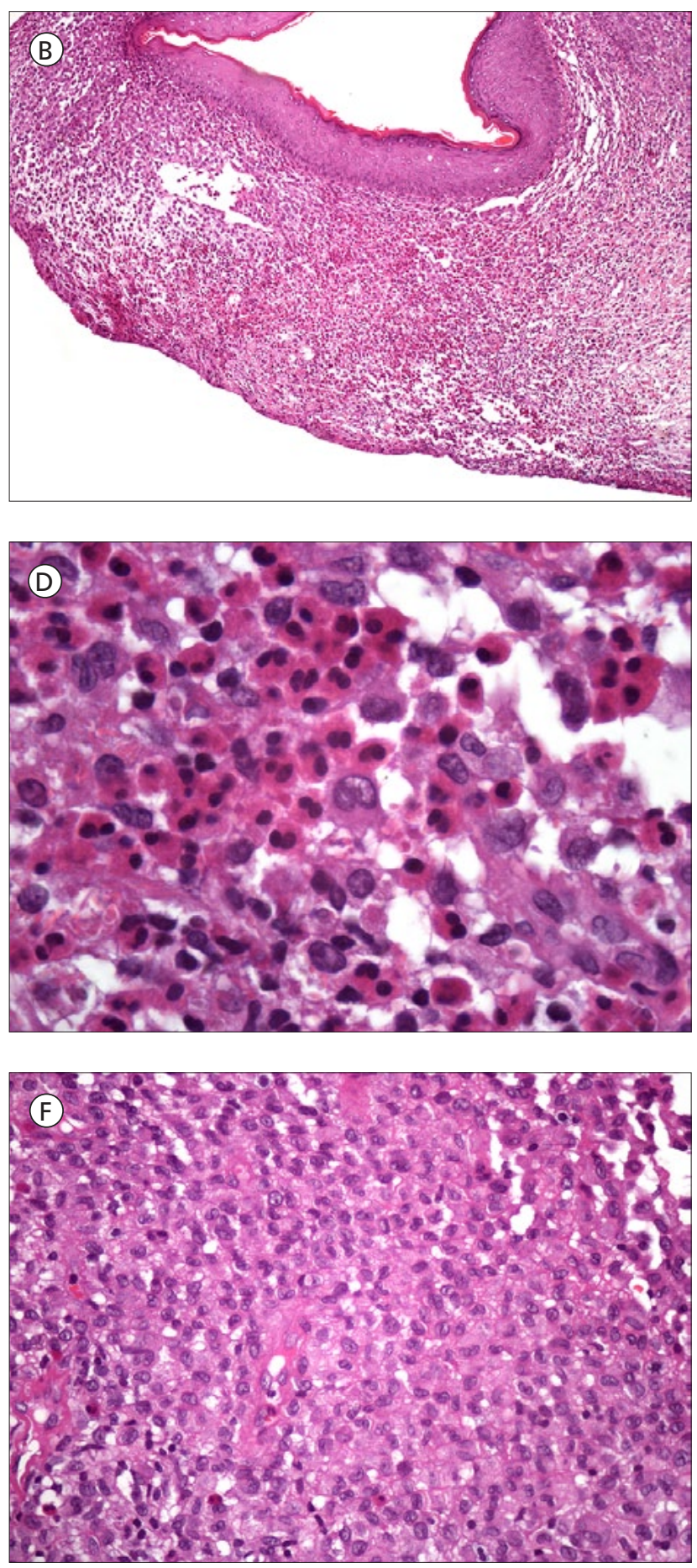

Figure 3. (A) Langerhans cell histiocytosis, perineal lesion, scanning magnification. Note the dense band-like cellular infiltrate in the dermis and ulceration at the right side of the section (H\&E, x20). (B) Band-like cellular infiltrate in the superficial and middle dermis. The intense pink areas correspond to clusters of eosinophils and the paler pink areas correspond to groups of abnormal Langerhans cells (H\&E, x100). (C) Abnormal Langerhans cells with vesicular cleaved nucleus and numerous intermingling eosinophils (H\&E, x400). (D) Cytological details of abnormal Langerhans cells. Note the amphophilic abundant cytoplasm and the large cleaved vesicular nucleus. The cell in the center of the photomicrograph has the appearance of a kidney (H\&E, x1000). (E) Dense infiltrate of Langerhans cells forming a sheet in the dermis and blurring the dermoepidermal junction (H\&E, x100X). (F) A sheet of abnormal Langerhans cells (H\&E, x400). (G) Cytological details of abnormal Langerhans cells. Note the coffee bean and kidney shapes of the large cleaved nucleus (H\&E, x1000). [Copyright: @2012 Jeunon et al.] 


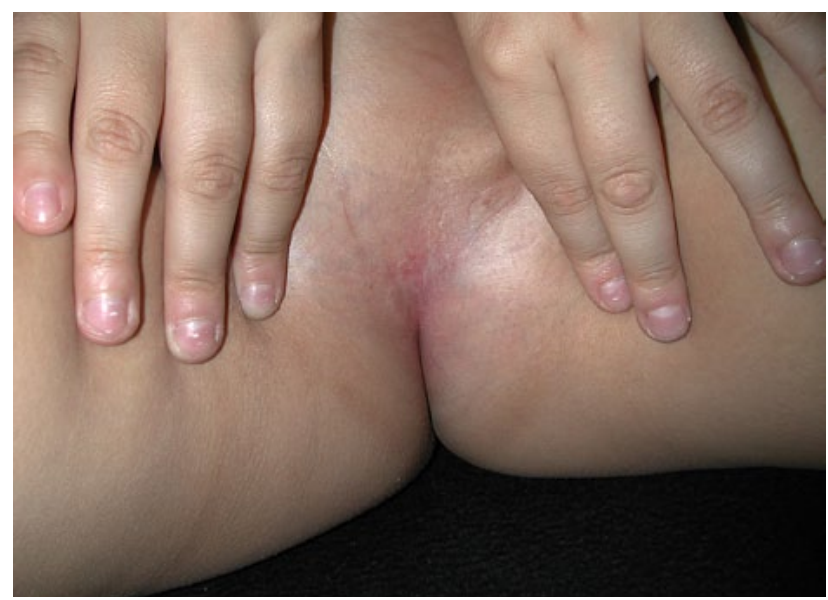

Figure 4. Complete healing of the perineal lesions after chemotherapy. [Copyright: @2012 Jeunon et al.]

ent in mucous membranes and may become crusted and ulcerated [7].

A presumptive diagnosis is based mainly on the recognition of the abnormal Langerhans cells in the dermis and, eventually, permeating the epidermis and epithelial structure of the anexa [3,5]. These cells are morphologically distinctive by virtue of their single large, vesicular, opened-chromatin, cleaved nucleus, with shapes resembling the silhouette of a kidney or a coffee bean and their abundant eosinophilic to amphophilic cytoplasm. The infiltrate composed of Langerhans cells may vary from dense to sparse and might have many intermingling inflammatory cells, particularly eosinophils. A definitive unequivocal diagnosis requires demonstration through electron microscopy of intracytoplasmatic Birbeck bodies or immunostaining of the cells by anti-CD1a and anti-S100 antibodies, with negativity for anti-CD68 [5, 8]. Langerin is another useful highly specific Langerhans cell marker.

The evaluation of the extent of the disease and the therapy of choice in each case involves a multidisciplinary team of clinicians/pediatricians, dermatologists, pathologists, hematologists, endocrinologists, radiologists and orthopedists.

The therapeutic approach to $\mathrm{LCH}$ depends upon the number and extent of the lesions, number of organs affected, age of the patient, presence of involvement of liver, lungs, spleen or hematopoietic system and of any organ dysfunction. In most patients with limited cutaneous disease, an expectant management usually is enough, but topical steroids can be used too in selected cases $[9,10]$. Isolated skin lesions may be surgically excised, while more extensive skin disease might be managed with psoralen-UVA phototherapy, photodynamic therapy or topical nitrogen mustard [6,1114]. Localized bone lesions are managed with curettage, for diagnostic and therapeutic proposes, intralesional steroids, or low-dose radiation [15]. For "multi-organ" disease, especially the high-risk group, prednisone alone or prednisone plus chemotherapeutic drugs, vincristine or etoposide being the most widely used, have been advocated by Histiocytosis Society protocols $[1,13]$.

There is still much controversy about the ideal approach in these cases, and study groups around the world are being conducted to clarify it [10].

\section{References}

1. Crooks B, Grenier D. Langerhans cell histiocytosis: A complex recurrent disease. Paediatr Child Health. 2010;15(2): 69-70.

2. Abla O, Egeler RM, Weitzman S. Langerhans cell histiocytosis: current concepts and treatments. Cancer Treat Rev. 2010;36(4):354-9.

3. Ackerman AB, Bennin B, Gotllieb GJ. Histopathologic Diagnosis of Inflammatory Skin Diseases. An Algorithmic Method Based on Pattern Analysis. 3rd ed. New York: Ardor Scribendi Ltd, 2005.

4. Ackerman AB, Mones JM. Langerhans' cell granulomatosis. In: Ackerman AB, Mones JM (eds.). Resolving Quandaries in Dermatology, Pathology \& Dermatopathology, vol 2. New York: Ardor Scribendi Ltd, 2001:222-7.

5. Li Z, Yanqiu L, Yan W, et al. Two case report studies of Langerhans cell histiocytosis with an analysis of 918 patients of Langerhans cell histiocytosis in literatures published in China. Int J Dermatol. 2010; 49(10): 1169-74.

6. Failla V, Wauters O, Caucanas M, Nikkels-Tassoudji N, Nikkels AF. Photodynamic therapy for multi-resistant cutaneous Langerhans cell histiocytosis. Rare Tumors. 2010; 2(2): e34.

7. Foley S, Panting K, Bell H, Leonard N, Franks A. Rapid resolution of primary vulval adult Langerhans cell histiocytosis with very potent topical corticosteroids. Australas J Dermatol. 2011;52(1): e8-e14.

8. Egeler RM, van Halteren AG, Hogendoorn PC, Laman JD, Leenen PJ. Langerhans cell histiocytosis: fascinating dynamics of the dentritic cell-macrophage lineage. Immunol Rev. 2010;234(1):21332.

9. Minkov M, Prosch H, Steiner M. Langerhans cell histiocytosis in neonates. Pediatr Blood Cancer. 2005;45(6): 802-7.

10. Satter EK, High WA. Langerhans cell histiocytosis: a review of the current recommendations of the Histiocyte Society. Pediatr Dermatol. 2008;25(3): 291-5.

11. Ng-Cheng-Hin B, O'Hanlon-Brown C, Alifrangis C, Waxman J. Langerhans cell histiocytosis: old disease new treatment. Q J Med. 2011;104(2): 89-96.

12. Hoeger PH, Nanduri VR, Harper JI, Atherton DA, Pritchard J. Long term follow up of topical mustine treatment for cutaneous langerhans cell histiocytosis. Arch Dis Child. 2000;82(6):483-7.

13. Arceci RJ, Brenner MK, Pritchard J. Controversies and new approaches to treatment of Langerhans cell histiocytosis. Hematol Oncol Clin North Am. 1998;12(2):339-57.

14. Aihara M, Hasegawa T, Okuyama Y, Hiruma M, Ikeda S. Langerhans cell histiocytosis treated with narrow-band ultraviolet B. J Dermatol, 2011; 38(2):151-4.

15. Margo CE, Goldman DR. Langerhans cell histiocytosis. Surv Ophthalmol. 2008;53(4):332-58. 